\title{
THE RANKING OF CHOSEN BRANCHES OF SADERAT BANK IN TEHRAN CITY THROUGH THE AHP AND THE DEA/AHP MODEL
}

\author{
Farkhonde Jabalameli \\ Faculty of Economic \\ University of Tehran \\ Tehran, Iran \\ E-mail: fameli@ut.ac.ir \\ Ehsan Rasolinezhad* \\ Faculty of Economic \\ University of Tehran \\ Tehran, Iran \\ E-mail: E.rasoli1984@yahoo.com
}

\begin{abstract}
Consistent economic units ranking is a significant and efficient issue in economic units' scope, one of the most important of which is banking industry.

In this paper we try to use the AHP and the combined Data envelopment analysis-Analytic hierarchy process (DEA-AHP) to rank the chosen branches of Saderat bank in Tehran. In this method, first we calculate a DEA model for pair wise branches and then we rank all these units through an AHP model. One of the most important outcomes of this paper is about city dividing which are not effective on branch ranking. It means that good feedbacks of branches are not related to a special zone in Tehran. Also the results of this ranking show the difference between AHP and DEA/AHP models.
\end{abstract}

Keywords: Bank branches, AHP, DEA/AHP

\section{Introduction}

Today banking sector plays a considerable role in the economic development and business improvement, in this aspect ranking of banks is vital. This ranking helps banks in improving their performance with respect to self and others; this in fact created a need for measurement of performance of banks. Banks perform their duties throughout their branches indeed branches are responsible to find out suitable customers. In order to control and analysis, banks managers have graded branches in 5 categories. These categories are excellent, $1^{\text {st }}, 2^{\text {nd }}$ and etc. But the next important subject after grading is ranking consistent branches to gain requisite analysis and advancement of these units through making legitimate rules. Considering this fact, using a safe and logical method for ranking is very remarkable. Regarding this case, there are a lot of methods in the whole world which the favorable and substantial model is named Analytic Hierarchy Process (AHP). This model has been founded by Professor Thomas L.Saaty in 1996 and now it is used by many experts in decision making ${ }^{1}$.

In this research we use the AHP model and a combination of AHP with DEA in case study of Saderat bank. It is necessary to inform that the DEA/AHP model has not been used in the humanities in Iranian bank industry and this article is the first attempt.

\footnotetext{
* Corresponding author

1 - AHP model was conceived and its theoretical underpinnings was developed by prof. Saaty and there is now an international society on the subject that meets every two years under the name of ISAHP
} 
In second section, we present some previous researches on AHP and DEA/AHP methods, these kinds of decision making models will be introduced. In forth section we investigate the methodology and in fifth section we analyze using AHP and DEA/AHP model in bank branches ranking and finally achieved results will be presented.

\section{Empirical Studies}

Many researchers have used the AHP method and the combined AHP/DEA model in their studies. Also many papers have been prepared with a focus on bank branches. In this section, we discuss these studies separately and briefly:

\subsection{Empirical studies in the AHP method}

Mukherjee and Das (2010) used the AHP as a tool for selection of important factors for the multidisciplinary evaluation of medical devices. Bhattarai and Adhicari (2009) have discussed the initial development and pilot testing performed in 2007, and subsequent improvement and use of the multi criteria analysis based sustainability monitoring framework by various partners of WaterAid Nepal. Islam (2009) investigated the Malaysian vision 2010 through AHP model. In the Onar and Polat (2009) research an AHP model was applied to selecting strategic options. Rasolinezhad (2009) evaluated electronic banking systems in developing nations using AHP model. Larson and Forman (2007) for selecting project scope for video logging and pavement condition data collection used the AHP model. Berrittella and ET, al (2007) evaluated the transport policies to reduce climate change impacts through an AHP model. In 2005, Grandzol improved the faculty selection process in higher education and in his research he used an AHP model.

\subsection{Empirical studies in combined AHP/DEA model}

Cai and $\mathrm{Wu}$ in their study in 2001 about financial evaluation, in a first step through AHP method, analyzed and adjusted financial evaluation systems and in a second step through DEA method presented a model, the results of which are showing efficient units.

Stern and et.al in 2000 have used a quantity- quality approach. In this research, the combined model is presented in 2 steps to rank decision making organizational units. In a first step, the DEA model is used for each pair of units and their efficiency is compared. In a second step a pair wise comparison matrix is constructed to rank units in accordance with AHP analysis.

Mohammadi and Hoseinizade in 2007 have ranked insurance agencies in Iran through the combined AHP/DEA model. In this article, first one DEA model was calculated for each pair of agencies, then a pairwise comparison matrix was constructed and at last with using AHP model, ranking was completed. In a study by the name of "Evaluating Science and Industrial University faculties of Iran from 1998-1999 using AHP/DEA method" that was done by Fattahi at 2000, the two-step mathematical model was used. Nakhaee (2003) after identification of operational criteria, used DEA method to measure faculties' efficiency in two educational and research dimensions. In this paper for each faculty, management and scale efficiency were analyzed and at last faculties' ranking was done by AHP model.

\subsection{Empirical studies in Bank Branches}

Sherman and Gold (1985) developed a method in which they determine the projection onto the frontier not by reducing each of the inputs by the same proportion as in the oriented methods but rather, by using the weighting scheme provided by the dual prices to calculate a composite point on the frontier. Sherman and Landine (1995) in their paper about Management of Bank efficiency used DEA model through 5 inputs and 4 outputs investigated 33 bank branches. The results of their research were shown 23 branches in inefficiency position. Fatahpoor (2002) in his M.S thesis searched 28 Melli bank branches in Iran. Jermic and Vajcic (2003) used a DEA to analyze efficiency of the banks in Croatian banking market from 1995 until 2000. From this research, it appeared the most significant cause of inefficiency among state owned and old banks. Hadian and Azimi (2005) investigated 10 Iranian Banks which contained 6 governmental banks and 4 private banks for their efficiency. Molaee (2008) in his thesis investigated 
Refah bank branches using TOPSIS model. Poorkazemi (2008) in his research "Grading of Bank branches" graded 2005 Tejarat Bank branches in Iran through Taxonomy model. He used 24 factors in his essay.

\section{Analytic Hierarchy Process (AHP)}

Analytic hierarchy process (AHP) is becoming quite popular in research due to the fact that its utility outweighs other research methods. The development of AHP could be traced back to the early 1970s in response to the scarce resources allocation and planning needs for the military. AHP is a hierarchical representation of a system. A hierarchy is an abstraction of the structure of the system, consisting of several levels representing the decomposition of the overall objective to a set of clusters, sub- clusters, and so on down to the final level. We can show AHP method through four steps that can be summarized in two phases. The first phase is a designing phase and the second an evaluating phase (Figure.1).

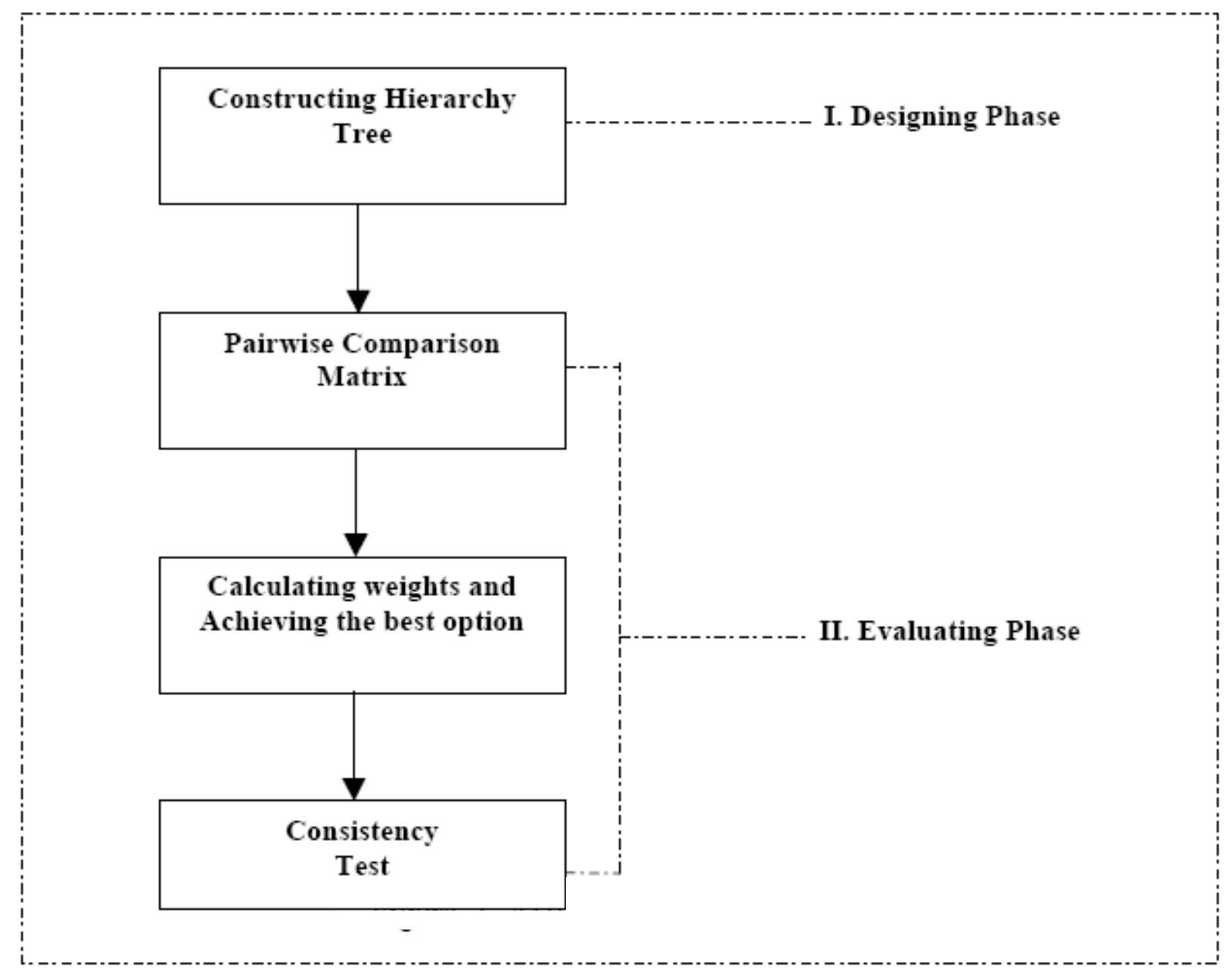

\section{DEA/AHP Approach}

Figure 1. The AHP framework

AHP/DEA approach is a kind of two- step approaches to gain Decision Making Units (DMU). In this method, first a DEA model is chosen for each pairwise unit without including other units. After that through the achieved results from DEA model, a pairwise comparison matrix is constructed and with AHP model, the full ranking is completed. The steps of this approach are done as follows: 
Step 1: Pairwise Comparison Matrix through DEA model:

Suppose that there is $n$ unit. Each unit has $m$ input and $s$ output. $x_{i j}$ is $i^{\text {th }}$ input in $j^{\text {th }}$ unit and $y_{r j}$ is $r^{\text {th }}$ output in $j^{\text {th }}$ unit. For each $A$ and $B$ pair, one DEA model is constructed as below:

$$
\begin{aligned}
& E_{A A}= \max _{u_{r}, v_{i}} \sum_{r=1}^{s} u_{r} y_{r A} \\
& s t: \sum_{i=1}^{m} v_{i} x_{i A}=1 \\
& \sum_{r=1}^{s} u_{r} y_{r A} \leq 1 \\
& \sum_{r=1}^{s} u_{r} y_{r B}-\sum_{r=1}^{m} v_{i} x_{i B} \leq 0 \\
& u_{r}, v_{i} \geq 0 \quad(r=1,2, \ldots, s)(i=1,2, \ldots, m)
\end{aligned}
$$

$E_{A A}$ is the amount of optimized efficiency of unit $A$. If unit $A$ is efficient, then $s_{2}=0$ and $s_{3} \geq 0$ and if unit A is not efficient then $s_{2} \succ 0$ and $s_{3}=0$. Other variables are zero. To achieve the best crossover evaluation for unit $B$, following models are designed:

$$
\begin{aligned}
& E_{B A}=\max Z_{B A}=\sum_{r=1}^{s} u_{r} y_{r B} \\
& \text { st }: \quad \sum_{i=1}^{m} v_{i} x_{i B}=1 \\
& \quad \sum_{r=1}^{s} u_{r} y_{r B} \leq 1 \\
& \sum_{r=1}^{s} u_{r} y_{r A}-E_{A A} \sum_{i=1}^{m} v_{i} x_{i A}=0 \\
& u_{r}, v_{i} \geq 0 \quad(r=1,2, \ldots, s)(i=1,2, \ldots, m)
\end{aligned}
$$

$E_{B A}$ is optimized crossover evaluating of unit $B$. In accordance with the two above models, $B B$ and $A B$ must be solved to calculate $E_{B B}$ and $E_{A B}$. So four DEA models are solved and amounts of $E_{A A}, E_{B A}$ , $E_{B B}$ and $E_{A B}$ are calculated. With the results of this model and using the below relation for each $i$ and $j$ units, each $a_{j k}$ element of pair wise comparison matrix is calculated as following equation, as shown.

$$
a_{i j}=1 \quad \text { if } \quad i=j, \quad a_{j k}=\frac{E_{i j}+E_{j k}}{E_{k k}+E_{k j}}
$$

Step 2: Ranking through AHP model:

In according to pairwise comparison matrix, in a second step, an analytical hierarchy process is constructed to calculate maximum Eigen value $\left(\lambda_{\max }\right)$ and Eigen vector $(\vec{w}) . j{ }^{\text {th }}$ element in $\vec{w}$ vector shows the relative importance of $j^{\text {th }}$ unit. The units that have maximum of $\vec{w}$ take the first place in the ranking. 
This implied method has some advantages. Firstly, inconsistencies in AHP method are removed and secondly, the problem of proportional of number of units and inputs and outputs are eliminated too.

\section{Research Methodology}

In this paper, seventy five Saderat bank branches were evaluated. We tried to choose equal (Homo) branches in reference to their activity scope. After selection of branches, each of their inputs and outputs are investigated. Choice of inputs and outputs is according to branches control on their variables. About Input variables, Number of fix staffs $\left(X_{1}\right)$, Amount of surface $\left(X_{2}\right)$ and on the output variables issue, Bank cards $\left(Y_{1}\right)$, ATM transaction $\left(Y_{2}\right)$, Number of Services $\left(Y_{3}\right)$, Deposits $\left(Y_{4}\right)$, Facilities $\left(Y_{5}\right)$ and Non-repayment Loans $\left(Y_{6}\right)$ are selected. We must note that all statistics of variables were obtained in October 2009 by means of interviewing and some related data from Saderat Bank database.

Each element in pairwise comparison matrix is calculated from four DEA model. The relevant element in a pairwise comparison matrix will be calculated. This element refers to the first row and the second column in the matrix. Results of these calculations for 75 branches are constructing a pairwise comparison matrix through 1200 linear programming models and calculations of $625 a_{i j}$ elements. Then we used a pairwise comparison matrix. It is important to note that, because of using DEA method, the matrixes are consistently compatible. Besides this combined model, we run our model using a simple AHP method. For this purpose we arranged 19 factors in 5 clusters deposits (A), Electronic banking (B), General (C), Services (D) and Facilities (E). After that we used 10 expert men for judge.

\section{The Results and Recommendations}

Both of the quality and quantity models have some problems. In this paper, in order to avoid these problems, we use the AHP/DEA approach and we use an AHP method for comparing. In this way, at first we used DEA method to construct a pairwise comparison matrix and then to rank, we used AHP method. Besides we design an AHP framework and rank these chosen branches again. Our tested units were 75 chosen branches in Saderat Bank of Iran. The results of this paper showed that in first grade branches, branch " $\mathrm{D}$ " has maximum weight and vice versa branch "B" has minimum weight. Moreover it appeared branch " $C$ " has maximum weight through AHP method and branch " $F$ " has minimum weight here. We found these 2 models have different ranks which depend on the relationship between factors.

We recommend the best branches (like " $D$ " in first grade, "V" in second grade and "S"'" in third grade branches) as a pattern for other branches which can improve and extend their level through following these top branches. Additionally we recommend bank managers to use this rank for making any bonus.

\section{REFERENCES}

A. Azadeh, S.F. Ghaderi, H. Izadbakhsh, (2008). Integration of DEA and AHP with computer simulation for railway system improvement and optimization. Journal of Applied Mathematics and Computation, Vol. 195, 775-785.

Adel,Azar and Gholamrezaee, Dawood, (2006). Ranking of Iranian States using DEA model. The Journal of Economics Research, Vol. 8, 153-173. [In Persian Language]

Bhattari, Shashi and Barun Kanta Adhikari, (2009). Analytic Hierarchy Process for Rural Micro Project Sustainability Monitoring in Nepal. ISAHP2009, Pittsberg, USA.

Cai, Yuezhou and Wenjiang, Wu.,(2001). Synthetic Financial Evaluation by a Method of Combining DEA with AHP. Journal of International Transactions in Operational Research, Vol.8. 
Chun Chu Li and Chia-yon Chen, (2004). Incorporating Value Judgment in to DEA to improve Decision Quality for Organization. The Journal of American Academy of Business, No.3, 423-427.

Islam, Rafikul, (2009). Prioritizing Issues of Malaysian Vision 2020: An Application of The Analytic Hierarchy Process. ISAHP2009, pittsberg, USA.

Karpela, Jukka., Antti Lehmusvaara and Jukka Nisonen,.(2007), Warehouse Operator Selection by Combining AHP and DEA Methodologies. International Journal of Production Economics, Vol.108, $135-142$.

Mohammadi, Ali and Seyed Mohammad Hoseinizade, (2008). Using DEA/AHP in Ranking of Insurance Agents. The journal of Economics Research, Vol.7, No.3, 281-303.

Molaee, Hamidreza, (2004). Evaluating the Efficiency of Refah Bank Branches. The thesis of M.S degree in Management faculty of University of Tehran.

Mukherjee, Bani and Pitamber Das, (2010). The Use of the Analytic Hierarchy Process as a Tool for Selection of important Factors for the Multi- Disciplinary Evaluation of Medical Devices. International Journal of Academic Research, Vol.2, No.1, 37-42.

Onar, Sezi cevik and Seckin Polat, (2009). An AHP Model for Selecting Strategic Options. ISAHP2009, pittsberg, USA.

Poorkazemi, Mohammad hossein, (2008). The Grading of Bank Branches. The Journal of Economics Research, Vol.7, No.3, 305-348.

Ramakrishnan, Ramanhatan.(2004). Data Envelopment Analysis for Weight Deviation and Aggregation in the AHP. Journal of Computation and Operation Research, Vol.33, 1289- 1307

Sinuany- Stern, Zilla., Mehrez, Abraham and Yossi Haddad,(2000). An AHP/DEA Methodology for Ranking Decision Making Units". Jounal of International Transactions in Operational Research, Vol.7, 75-112.

Vujcic, b. and I. Jemric,(2001). Efficiency of Banks in Transition:A DEA Approach, Journal of Croation National Bank, Dubrovnik, 1-125. 